\title{
Neighbors consistently influence growth and survival in a frequently burned savanna
}

\author{
Mark Davis ${ }^{1}$ and Richard Condit ${ }^{2}$ \\ ${ }^{1}$ Macalester College \\ ${ }^{2}$ Morton Arboretum
}

December 10, 2021

\begin{abstract}
Successful management of savannas is challenging and requires knowledge of the causes and consequences of the spatial arrangement of the trees. In savannas, trees are often aggregated, and the ability of trees within the clumps to survive fires plays a significant role in determining the savannas landscape dynamics. Whether or not a tree survives a fire is often dependent on the nature of their interactions with neighboring trees, positive or negative. In cases where disturbances are episodic, detecting these interactions is only going to be possible through long-term studies. Data reported here, from twenty-five years of annual tree censusing of a large grid-plot in a frequently burned savanna, showed consistent neighbor facilitated survival, irrespective as to whether the neighbors were conspecifics or heterospecifics. The positive interactions likely involve the reduction of both herbaceous and woody fuel in denser sites, and possibly mycorrhizal sharing among nearby trees.
\end{abstract}

\section{INTRODUCTION}

Successful management of fire-prone woody ecosystems is challenging and requires knowledge of the spatial arrangement of the trees (Meyer et al. 2008, Das et al. 2008, Larson and Churchill 2012, Medens et al. 2019, Furniss et al. 2019) and how the tree distribution patterns influence the nature and consequences of subsequent fires (Turner 1989, Pacala and Deutschmann 1995, Frelich et al. 1998, Stephens et al. 2008). Tree aggregation, or clumping, is an especially common distribution pattern (Armesto et al. 1986, Condit et al. 2000, Peterson 2020), particularly in environments experiencing periodic fires, such as savannas (Rebertus et al. 1989, Davis et al. 2005, Bacelar et al. 2014, Staver et al. 2019, Tamjidi and Lutz 2020).

Savannas are notably dynamic ecosystems, in which intensity, frequency, and patterns of fire determine whether the savanna is maintained or if it begins to transition into a grassland or forest. Fire intensity in savannas is related to the abundance of grasses, the primary fuel in these environments (Frost and Robertson 1987, Holdo 2005, Archibald et al. 2009, Hoffmann et al. 2012). Since grass biomass is lower under savanna tree canopies (Scholes 2003, Peterson et al. 2007), the ability of trees within the clumps to survive the fires will play a significant role in determining the larger scale landscape dynamics.

Small-scale tree spatial patterns can be influenced by interactions among neighbors, both negative and positive, the latter including providing refuge from physical stress (Baumeister and Callaway 2006, Tirado and Pugnaire 2015), reducing susceptibility to enemies (Pineda et al. 2010), suppression of a strong competitor (Lutz et al. 2014), and mycorrhizal sharing (Simard et al. 1997, Bennett et al. 2005, Das et al. 2008, Tamjidi and Lutz, 2020, Germain and Lutz 2021). In the case of savannas, if positive neighbor interactions result in the increased survival of individual trees, then they would also lead to the persistence of the clumps of trees, which in turn would promote the ongoing perpetuation of the savanna. However, the savanna will continue to exist only if the positive neighbor interactions persist consistently over time. 
As emphasized by Brooker and Callaghan (1998), in cases where disturbances are episodic, detecting positive interactions among neighbors is only going to be possible through long-term studies. This is especially true for studies trying to determine whether positive interactions in response to disturbances remain consistent over time. To conduct such research, a study would require a temporal scale long enough for multiple disturbances to occur, along with a spatial scale large enough to include many trees and tree neighborhoods. We are not aware of any such study.

The primary purpose of this study was to determine the nature of neighbor interactions among trees in an oak savanna experiencing frequent fires, and to what extent these interactions are sustained over time. We were able to do this using data obtained from a large grid-plot study in which trees were censused annually for twenty-five years, during which time the trees experienced between nine and eleven fires. The long-term observations allowed us to test how local tree density effects growth and survival of individuals in the face of repeated fires, and, secondarily, whether certain small-scale abiotic factors are important to a tree's fate.

\section{MATERIALS AND METHODS}

\section{Study Area}

This study was conducted in east-central Minnesota at the Cedar Creek Ecosystem Science Reserve (CCESR) (Latitude: 45.401, Longitude -93.201) located in the Anoka Sandplain, a glacial outwash area with coarsetextured soil low in organic matter and total nitrogen (Grigal et al. 1974). Maintained by fire, prairie and oak savanna were dominant upland vegetation types in the Anoka Sandplain prior to European settlement (Wovcha et al. 1995). The oak savanna/woodlands at CCESR are characterized by low tree diversity. They are dominated by two species of oaks, Quercus macrocarpa Michx and Quercusellipsoidalis E. J. Hill, accompanied by varying abundances of a small number of mesophytic species, depending on the burn frequency (Peterson and Reich 2001). In 1964 a program of prescribed burns (ranging from controls to annual burns) was initiated at CCESR to restore and maintain oak savanna and to study the effects of fire on vegetation (Irving 1970).

\section{Study Grid}

During 1988, one of us (MD) initiated the GLADES (G rid forL andscape A nalysis and DE mographicS tudy) Project with the establishment of a square 16 ha grid (consisting of $160010 \times 10 \mathrm{~m}$ cells) in a portion of the CCESR oak savanna/woodland habitat. In 1995 and 1996, nearly nine thousand trees with a dbh (diameter at breast height) of at least $2 \mathrm{~cm}$ were tagged, each with a unique number. Their dbh and x,y location within the grid were also recorded (Davis 2021). A burn program was instituted in the grid area in 1987, and the study grid contains three different burn units, with burn numbers in the units during the twenty-five-year study (1995-2020) ranging from nine to eleven (Davis 2021). Burns took place in late April or early May and were surface fires.Q. macrocarpa and Q. ellipsoidalis represented $90 \%$ of all the trees. All trees, including each of the stems of multiple-stemmed trees, were visited annually and their statuses (live, dead standing, or dead fallen) recorded. The dbh of live stems were measured every five years (Davis 2021).

\section{Stems vs Trees}

All analyses were conducted at the level of trees. For example, a tree was considered dead only if all stems were dead. Basal area of a tree consisted of the summed basal areas of all live stems. Note: while many top-killed trees resprouted, the frequent fires prevented the sprouts from persisting and replacing any killed trees (Davis 2021).

\section{Growth}

Growth rate was defined as the increment in dbh divided by the time between measurements. All census intervals were exactly 5 years because censuses were carried out at the same time (late spring) each year, within fifteen days. When multiple stems of a tree survived, only growth of the largest stem in the earlier census was used in analyses. If two stems were the same size, one was chosen at random.

\section{Growth distribution and transformation}


In tree species, the distribution of growth rates among individuals within a species is typically highly rightskewed, and this was the case in the two dominant species, Q. macrocarpa and Q. ellipsoidalis (Fig. 1a). It was thus necessary to transform growth, normalizing the distribution for use in statistical models relating growth to neighborhood density. Log-transformation would be routine but is invalid in this situation due to many growth rates of exactly zero (because of millimeter resolution in dbh). In this situation, one option is to convert zeros to the smallest positive growth rate that could be measured, in this case $1 \mathrm{~mm}$ dbh over 5 years. However, such an arbitrary value is a problem. When growth rates are low, the exact choice of a smallest positive has a large impact, because the logarithm varies rapidly at small numbers. In saplings, growth rates are typically $<1 \mathrm{~mm} \mathrm{y}^{-1}$, so arbitrarily converting 0 growth to 0.2 vs. 0.1 is a large difference and can affect results.

A better transformation is the square root, or some other similar power, while maintaining any negatives. Define growth $g$ as

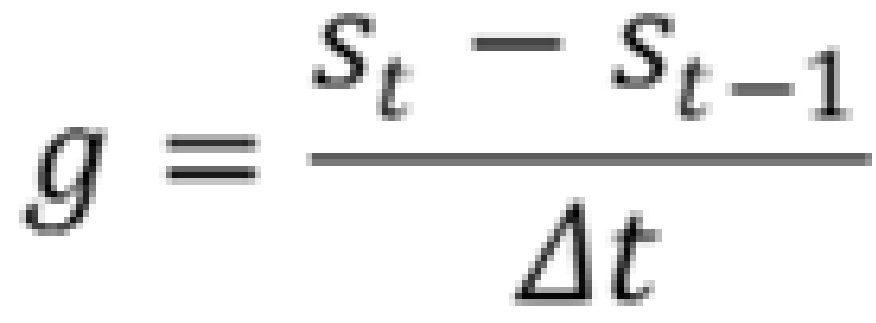

where $s_{t}$ is size (dbh) at time $t$ and $\Delta t$ is the time interval. Then the transformation $T$ is

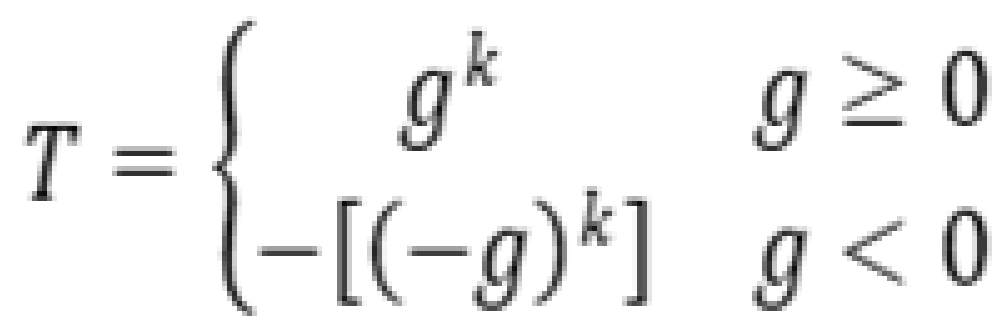

where $k>0$. If $k=0.5$, it would be a square root transformation, but we used instead $k=0.45$. Kenfack et al. (2014), tested skewness of $T$ across a range of values of $k$. Here we tested a similar range and found $k=0.45$ was effective at reducing skewness across a range of dbh categories (Fig. 1b).

\section{Neighborhood density}

For each tree, we located every other tree $<20 \mathrm{~m}$ away. This can be done efficiently in a large plot by first assigning every tree a cell number within a grid of $20 \times 20 \mathrm{~m}$. Then, inter-tree distances were calculated only for trees within the same cell or neighboring cells. That locates every tree within $20 \mathrm{~m}$ but reduces enormously the number of distances calculated. The identity of all neighbors alive during any given year and within $20 \mathrm{~m}$ of every tree was calculated and saved.

Neighbor density was defined as the basal area of all those neighbors that were alive in any one census. Neighbor density was divided into species groups. For every individual of $Q$. macrocarpa, the neighboring basal area was considered in two categories: conspecific, meaning all basal area of neighboring Q. macrocarpa 
, and heterospecific, that of all other species. Likewise, neighboring basal area of every Q. ellipsoidalis was divided into the same two groups, conspecific (other Q. ellipsoidalis ) vs. heterospecific (all species except Q. ellipsoidalis ). The two oak species so thoroughly dominate the study site that heterospecific basal area is nearly all due to the opposite oak. (In 1995, the two oak species represented more than $92 \%$ of the basal area in the study grid, which had increased to $95 \%$ by 2005 and $97 \%$ by 2020 (Davis 2021).)

We further subdivided neighbors by distance, 0-5, 5-10, and 10-20 m away from a focal tree, dividing basal area by surface area of each ring. In preliminary analyses, we found no difference in the impact of neighbors within $5 \mathrm{~m}$ and at 5-10 m, so we combined those categories. This left four measures of neighbor density, two taxonomic (heterospecific vs. conspecific) and two distance categories.

Because neighbor density was limited to a fairly small range, no transformation was necessary, matching other analyses of local density (Condit et al. 1994, Comita et al. 2010). We chose to measure neighborhood density in $\mathrm{m}^{2}$. ha ${ }^{-1}$, units we will refer to as condits . Specifically, we chose a magnitude of 10 condits as the density measurement because this was close to two standard-deviations $(S D)$ of both conspecific and heterospecific density, in both distance categories, for the two abundant species. For example, the $S D$ of neighbor density around $Q$. ellipsoidalis individuals in the four categories was between 3.5 and 8.9 condits (across all five censuses); in Q. macrocarpa, it was 3.1-7.7 condits. This means that varying neighbor density by one condit indicated an increase that covered most of the range of density.

\section{Environmental Variables}

A tree's ability to access water and nutrients at CCESR would be expected to influence its vigor and potentially its vulnerability to fires. Due to the Anoka Sandplain's slight relief, CCESR has an elevation gradient of only ten meters. Because the water table at CCESR is quite flat and located at the lower end of the site's elevation gradient (Basiletti 2018), small differences in elevation in this sandy soil environment likely affect a tree's access to water. Similarly, tree hardiness is likely to be affected any spatial variation in soil nutrient levels.

Nitrogen . Nine soil samples were collected from each grid cell in 1989, mixed, dried, and analyzed for total $\mathrm{N}$ using alkaline persulfate digestion followed by $\mathrm{NO}_{3}$ measurement on a Technicon II Autoanalyzer.

Elevation. In 1989, Mark Hurd Corp. (no longer extant) collaborated with a local surveying company and produced a set of highly accurate and high-resolution topographic data for the site, consisting of a grid of elevation data (m above sea level) at points $3 \mathrm{~m}$ apart (meaning 9 points within each $10 \mathrm{x} 10 \mathrm{~m}$ cell). The elevation designated for each cell consisted of the mean of all elevation points within the cell. Elevation ranged from a low of $278.1 \mathrm{~m}$ and a high of $285.6 \mathrm{~m}$. Elevation was standardized by subtracting $278 \mathrm{~m}$, the minimum, and dividing by 7.5, the range. This meant that the unit of elevation, as for neighbor density, represented the entire range across the plot.

For each tree, a value for soil nitrogen and elevation was assigned from the closest grid cell center. The soil $\mathrm{N}$ and elevation variables turned out to be highly correlated $(\mathrm{r}=-0.552, \mathrm{p}<0.0001)$, and preliminary models suggested elevation was a better predictor of growth than soil $\mathrm{N}$. The growth and survival models thus included elevation, but not $\mathrm{N}$, as a predictor.

\section{Growth and survival as a function of neighborhood density and dbh}

A linear, multiple regression was used to relate growth to six variables: four measures of local neighborhood density, and elevation. Trees were divided into four size categories, 2-5, 5-10, 10-20, and 20+ $\mathrm{cm}$ dbh (each category open on the right, so [?] 5 and $<10$, etc.). This allowed each size category to have different responses. Stem diameter was included as a predictor within each category because growth changes considerably with size, especially in small trees. Growth was calculated in five census intervals, each lasting five years, and the census was included in the model as a random effect, accounting for the repeated growth measurements of the same individual trees. The models were run separately in the two species, Q. macrocarpa and $Q$. ellipsoidalis, meaning there were eight models all told, four dbh categories in two species. The survival model was parallel in all aspects, but with logistic regression replacing linear regression. 


\section{Parameter fitting}

Regression parameters were estimated using a Bayesian Monte Carlo procedure. For growth, the model was based on a Gaussian error term; for survival, the error was binomial. The post burn-in chain of estimates produced a posterior distribution for every parameter, and statistical confidence in every parameter was estimated as $95^{\text {th }}$ percentiles from the posterior distributions (or $95 \%$ credible intervals). Models were run 10000 steps, and the first 2000 discarded as burn in. Chains were examined visually and converged in < 1000 steps. Details of the method are given elsewhere (Condit et al. 2006, 2007).

Results are presented as effect sizes of the four neighborhood predictors and elevation on growth and survival of stems in each of the top three size categories. Results for the smallest size class, $2-5 \mathrm{~cm}$ dbh were not reported in detail because the number of trees in this size class declined substantially during the study due to their high mortality rates during the burns (no live small pin oaks remained by the end of the study), making it impossible for the models to yield reliable results for the latter time periods.

In the case of growth, these are partial regression coefficients from the linear regression (i.e., the regression parameters for each predictor); these were divided by standard deviations in each dbh class and species. Since predictors (neighbors and elevation) were standardized so one unit means approximately the entire range, a growth effect of 1.0 means that growth varied by an amount equal to its standard deviation across the full range of the predictor. Survival rates cannot be transformed with a standard deviation, but effect sizes can be transformed so that they display the change in survival across the range of a predictor. We do not report the dbh effect, since the four dbh categories allow conclusions about neighborhood effects and tree size; dbh was in the model only as a precaution to avoid misinterpreting the density effects.

\section{RESULTS}

\section{Survival}

Neighbor density. In both Q. macrocarpa and Q. ellipsoidalis, neighborhood density, both heterospecific and conspecific, was positively associated with survival likelihood. Effects were consistent across dbh classes and censuses (Figs. 2 and 3). The effect of neighbors did not diminish with distance. Effect sizes were often +0.5 up to +0.9 . To reach effects $>0.8$ means survival would increase from $10 \%$ per 5 years without neighbors to $90 \%$ with dense crowding.

The two species differed in detail. Indeed, both benefited most by having Q. macrocarpa neighbors, that is, the conspecific effects in $Q$. macrocarpa were stronger than the heterospecific, but just the opposite in Q. ellipsoidalis (Figs. 2 and 3). Note: while small sample sizes of the $2-5 \mathrm{~cm}$ dbh trees during the latter time intervals made it impossible to model these trees throughout the study, during the first two intervals, the survival effects of neighbors for these trees were similarly consistently positive. As in the larger trees, small Q. macrocarpa were best protected by conspecifics, while small $Q$. ellipsoidalis were best protected by heterospecifics.

While neighbor facilitation with respect to tree survival persisted throughout the study, and in most cases remained strong after twenty-five years, the data showed a slight but consistent downward trend in the strength of this relationship (Figs. 2 and 3).

Elevation. Survival generally was not significantly associated with elevation. Few tests were significant, and those that were significant were inconsistent in direction, so we omit the effect sizes.

\section{Growth}

Conspecific density. In both Q. macrocarpa and Q. ellipsoidalis, growth was consistently negatively associated with conspecific neighbor density (Figs. 4 and 5). Effects reached -0.5 to -0.6 , meaning that growth changed by half its standard deviation across the range of neighbor density, although most effects had lower magnitudes. The negative effect of conspecifics was consistent across censuses in both species. In both species the impact of the nearest conspecifics, those $<10 \mathrm{~m}$ away, was stronger than the impact of neighbors 10-20 m away, though some significant negative effects persisted at the greater distance (Figs. 4 and 5). 
There were differences in detail between the two species, however. InQ. macrocarpa, the largest dbh category, trees [?] $20 \mathrm{~cm}$, was unaffected by conspecific neighbors (Fig. 4); only smaller trees were inhibited. In contrast, all dbh categories in Q. ellipsoidalissuffered lower growth near conspecifics (Fig. 5), though the 5-10 cm class in Q. ellipsoidalis had small samples and erratic results.

Heterospecific density. The two species were quite distinct in their response to heterospecific neighbors. $Q$. macrocarpa was negatively impacted in all censuses and all dbh categories (Fig. 4). In the largest dbh class $(>20 \mathrm{~cm})$, this impact of heterospecifics contrasted with the lack of impact of conspecifics. In contrast, Q. ellipsoidalis was not affected by heterospecific neighbors (Fig. 5). Effect sizes were positive more often than negative, but no effects were significantly different from zero. The small sample sizes of the smallest size class $(2-5 \mathrm{~cm}$ dbh) made it difficult to discern a relationship between neighbor density and growth, but where significant, they were negative (reduced growth with more neighbors).

Elevation. Elevation had a significant negative effect on growth in both species, meaning trees grew fastest at lower elevations. The effect size was around -0.1 in most cases where it was significant, though it reached -0.3 to -0.4 in the Q. ellipsoidalis trees $5-10 \mathrm{~cm}$ in diameter.

\section{DISCUSSION}

\section{Survival}

This is the first study to document consistent neighbor facilitation among trees experiencing repeated stressors over an extended time period. Trees of all sizes in close proximity with neighbors were considerably more likely to survive fire throughout the study. Our findings support the literature documenting positive neighbor effects among plants in stressful and highly disturbed environments (Bertness and Callaway 1994, Brooker et al. 2008, Guo et al. 2021).

We believe three factors contributed to this neighbor facilitation in terms of survival. The first involves the reduction of herbaceous fuel under tree canopies. The decline in fire frequency and intensity, and the associated decline in tree mortality that occurs when savannas transition to forests, is believed to be due to the reduced biomass of grasses, which are the primary fuel for surface fires in these environments (Frost and Robertson 1987, Holdo 2005, Archibald et al. 2009, Hoffmann et al. 2012). Rebertus and Burns (1997) found that tree survival in Quercus savannas was inversely related to grass cover. At CCESR, grass abundance is strongly negatively associated with tree canopy cover in the oak savanna/woodland habitats (Peterson et al. 2007). Thus, more neighboring trees means less herbaceous fuel and hence less fire risk.

The second factor involves the reduction of woody fuel. While both oak species contributed to neighbor facilitation involving survival, the survival benefit of having $Q$. macrocarpa as neighbors exceeded the benefit of having neighboring Q. ellipsoidalis for both species (Figs. 2 and 3). We think the difference in firesusceptibility between the two oak species may account for this difference. Q. macrocarpa is considered among the most fire-resistant oaks, particularly as compared to Q. ellipsoidallis (Lorimer 1985, Frelich et al. 2015), illustrated by the much higher survival rate (260\% higher) of $Q$. macrocarpa during the study (Davis 2021). This means that Q. ellipsoidalis is more likely to serve as fuel, threatening the survival of their neighbors. Conversely, the more fire-resistant Q. macrocarpa is likely to impede the spread of fire, reducing the threat of fire-induced mortality among its neighbors. Belote et al. (2015) found the fire-resistant Larix occidentalisincreased survival rates among nearby trees in a similar way.

The third factor involves mycorrhizae symbioses. A common explanation for neighbor facilitation among plants involves mycorrhizal sharing (Francis and Read 1984, Hunter and Aarrsen 1988, Simard et al. 1997, Teste and Simard 2008, Das et al. 2008, van der Heijden and Horton 2009, Bennett et al. 2017, Germain and Lutz 2021). Q. macrocarpa and Q. ellipsoidalis are both ectomycorrhizal trees (Avis et al. 2003) and red and white oaks are known to share mycorrhizae (Walker 2003, Avis et al. 2008). Thus, we believe that mycorrhizal sharing among both conspecifics and heterospecifics may also be contributing to the survival-related neighbor facilitation documented in this study. Other possible explanations for the increased likelihood of trees with neighbors surviving fire involve the reduced wind speeds and higher moisture levels associated with denser 
sites (Hoffmann et al. 2012, Belote et al. 2015).

It is possible an analysis could identify a positive neighbor effect among trees when one does not actually exist. For example, a false positive could result if surviving trees tend to be clumped in desirable microhabitats (Guo et al. 2021). However, while we did not examine all factors that could contribute to a favorable microhabitat, our analyses did include elevation (distance to water table) and soil nitrogen levels, both of which may be expected to influence tree survival.

Although neighbor facilitation with respect to survival persisted throughout the study, remaining strong in most cases, the strength of this relationship slightly declined over time for most size classes among both species (Figs. 2 and 3). The documented decline in neighbor facilitation over time might be due to the substantial reduction in the number of trees during the study. Only about one-third of the trees that were alive at the start of the study were still alive in 2020 (Davis 2021). This means that the number of neighbors for most trees would have declined substantially during this time. As the difference in the magnitude of high and low neighbor measurements declines, the ability of the models to discern positive neighbor relationships would be expected to decline as well.

A second possible explanation for the decline in the strength of neighbor facilitation involves the arrival of oak wilt (Bretziella fagacearum ) in east-central Minnesota several decades ago (Gibbs and French 1980), and which is thought to have spread rapidly at CCESR since 2010 (Sapes et al. 2021, Pellegrini et al. 2021). The fungus is spread primarily through root grafting among neighboring trees and by sap beetles (Nitidulidae) (Kuntz and Riker 1956, Jagemann et al. 2018). Thus, while underground root and mycorrhizal connections may reduce the likelihood of fire-induced mortality for the two oak species, this same network could facilitate the transmittance of oak wilt.

It is possible, then, that oak wilt might have reduced the neighbor benefits over time. However, in a separate study at CCESR, Pellegrini et al. (2021) found that while oak wilt dramatically increased tree mortality in unburned areas, where trees are densely packed and which are dominated by Q. ellipsoidalis, it had little effect in frequently burned sites. Also, since species in the red oak group lack tyloses, they are not as able to effectively compartmentalize scarring injuries as are white oaks, thereby making them considerably more susceptible than white oaks to subsequent fungal infection (Gibbs and French 1980, Juzwik et al. 2011, Dey and Schweitzer 2018). However, while Q. macrocarpa is much less vulnerable to oak wilt than $Q$. ellipsoidalis , it exhibited a similar decline in neighbor facilitation. Thus, it seems unlikely oak wilt contributed much, if anything, to the decline in the strength of neighbor facilitation during the study.

\section{Growth}

Growth of both species was greater at lower elevations, likely because lower elevation sites were closer to the water table and were higher in soil nitrogen.

The overall negative association between growth and conspecific neighbors for both oak species of all size classes, except for large Q. macrocarpa trees, is consistent with expected outcomes of intra-specific competition (Adler et al. 2018, Yang et al. 2019). That growth in large Q. macrocarpa trees was not affected by neighboring conspecifics is not surprising. They are unlikely to be overtopped by neighboring conspecifics, and the fact that large $Q$. macrocarpa trees produce some of the deepest roots of all oaks (Deitschmann 1965, Johnson 1990) means they may be able to escape much of the underground competition with smaller Q. macrocarpa trees. Although growth in large Q. macrocarpa trees was not affected by conspecifics, it was negatively affected by heterospecific neighbors. This is likely due to interspecific competition with the much faster growing $Q$. ellipsoidalis, which grows (increase in dbh) three times faster than Q. macrocarpa (Davis 2021). Also, at this site Q. ellipsoidalis typically grows taller than Q. macrocarpa, meaning that even large Q. macrocarpa trees can end up growing in the shade of Q. ellipsoidalis .

Unlike Q. macrocarpa, Q. ellipsoidalis growth was not affected by neighboring heterospecifics. As emphasized above, by not serving as a good fuel, $Q$. macrocarpa is likely to impede the spread of fire. Since fire is known to reduce growth of surviving trees (Refsland et al. 2020), Q. macrocarpa would be expected to 
provide its neighbors some protection from growth reductions due to fire, thereby perhaps canceling out negative effects due to competition.

\section{Summary}

We found the ability of a tree to survive fires is greatly increased when it has neighbors, either conspecific or heterospecific. Particularly noteworthy is that we documented facilitated survival repeatedly over time. As shown in Figs. 2 and 3, neighbor facilitation increased survival rates during each of the five 5-year intervals. This persistent neighbor facilitation is likely due to the reduction of both herbaceous and woody fuel in denser sites, and possibly by mycorrhizal sharing among nearby trees. Our findings support the idea that facilitation among plants occurs more commonly in severe and highly disturbed environments (Walker and Chapin 1987, Brooker and Callaghan 1998), in accordance with the stress gradient hypothesis (Bertness and Callaway 1994). The fact that survival was enhanced by neighbor facilitation, while growth was often reduced by negative neighbor interactions, is consistent with the findings from a meta-analysis of the stress-gradient hypothesis by Adams et al. (2021), which showed that increasing stress tends to result in an increase in positive ecological interactions in terms of survival but an increase in negative interactions with respect to growth.

Based on a review of fifty studies of spatial pattern in fire-frequent forests, Larson and Churchill (2012) concluded that aggregated tree regeneration is the primary cause for the development and maintenance of tree clumps in these environments. In the study reported here, due to persistent neighbor facilitation, trees survived best growing in groups. Since the frequent fires prevented any significant tree regeneration in the study area, either through sprouting or seedling recruits (Davis 2021), the study showed that aggregated tree survival by itself can also be an important driver of post-fire tree clumping. The results reported here, along with those by Lutz et al. (2014) and Larson et al. (2015), emphasize the importance of documenting the spatial patterns of tree survival following fires, in addition to those of regeneration, to gain a fuller understanding of the processes creating the observed spatial patterns of savannas, woodlands, and forests. Given the number of recurrent fires during the study, the results should especially inform efforts to restore savannas through the implementation of frequent controlled burns.

The neighbor facilitation documented in this study may explain aspects of the evolution of Quercus . Compared to most North American hardwood trees, oaks are well adapted to survive periodic fires (Abrams 1992). Adaptations include thick bark, ability to resprout following top kill, and, in the white oak group, the ability to compartmentalize fire wounds (Brose et al. 2014). This study showed how being near to other oaks can also reduce fire mortality.

Explanations for the value of seed dispersal usually have emphasized only the benefits of dispersing away from the parent, i.e., avoiding disproportionate seed and seedling mortality near the parent, being able to colonize suitable sites unpredictable in space and time, and, through directed dispersal, being able to disperse to particular types of sites suitable for establishment and growth (Howe and Smallwood 1982, Wenny 2001). However, emphasizing that seeds dispersed close to the parent likely will encounter favorable environmental conditions, Snyder (2011) concluded that unless the environment is spatially and temporally highly unpredictable, short-distance dispersal is likely to be evolutionarily stable. The positive neighbor interactions reported here illustrate another value of not dispersing far from the parent. Thus, it is possible that neighbor facilitation may have played a role in the evolution of short-distance dispersing fruits, such as acorns.

\section{ACKNOWLEDGEMENTS}

This study could not have been conducted without the assistance of more than forty Macalester College students, who helped set up and monitor the woodland grid from 1988 through 2013. We thank Cathleen Nguyen, Rebecca Montgomery, and Jeannine Cavender-Bares for their censusing help during 2017-2019. We also thank David Bosanko, Dale Krueger, Jim Krueger, and Troy Mielke for conducting the controlled burns. Conversations with Jim Lutz and Sara Germain were very helpful during the writing of the paper. This research was supported by NSF grants BSR-8717847, DEB-9419922, DEB-9873673, and DEB-0208125 


\section{(M.A.D.)}

\section{REFERENCES}

Adler, P. B., D. Smull, K. H. Beard, R. T. Choi, T. Furniss, A. Kulmatiski, J. M. Meiners, A. T. Tredennick, and K. E. Veblen. 2018. Competition and coexistence in plant communities: intraspecific competition is stronger than interspecific competition. Ecology Letters 21:1319-1329.

Archibald, S., D. P. Roy, B. W. van Wilgen, and R. J. Scholes. 2009. What limits fire? An examination of drivers of burnt area in Southern Africa. Global Change Biology 15:613-630.

Armesto, J. J., J. D. Mitchell, and C. Villagran. 1986. Patterns of Trees in Some Tropical and Temperate Forests. Biotropica 18:1-11.

Avis, P. G., D. J. McLaughlin, B. C. Dentinger, and P. B. Reich. 2003. Long-term increase in nitrogen supply alters above- and below-ground ectomycorrhizal communities and increases the dominance of Russula spp. in a temperate oak savanna. New Phytologist 160:239-253.

Avis, P. G., G. M. Mueller, and J. Lussenhop. 2008. Ectomycorrhizal fungal communities in two North American oak forests respond to nitrogen addition. New Phytologist 179:472-483.

Bacelara F. S., J. M. Calabrese,and E. E. Hernández-García. 2014. Exploring the tug of war between positive and negative interactions among savanna trees: Competition, dispersal, and protection from fire. Ecological Complexity 17:140-148.

Basiletti, M. 2018. Depth to water table ver 8. Environmental Data Initiative. https://doi.org/10.6073/pasta/ebb842499dfdbc6e542b03e3f17741a9

Baumeister, D., and R. M. Callaway. 2006. Facilitation by PPinus flexilis during succession: a hierarchy of mechanisms benefits other plant species. Ecology 87:1816-183.

Belote, T. R., A. J. Larson, and M. S. Dietz. 2015. Tree survival scales to community-level effects following mixed-severity fire in a mixed-conifer forest. Forest Ecology and Management 353:221- 231.

Bennett, A. E., J. Alers-Garcia, and J. D. Bever. 2005. Three-way interactions among mutualistic mycorrhizal fungi, plants, and plant enemies: hypotheses and synthesis. American Naturalist 167:141-152.

Bennett, J. A., H. Maherali, K. O. Reinhart, Y. Lekberg, M. M. Hart, and J. Klironomos. 2017. Plant-soil feedbacks and mycorrhizal type influence temperate forest population dynamics. Science 355:181-184.

Bertness, M. D., and R. Callaway. 1994. Positive interactions in communities. Trends in Ecology and Evolution 9:191-193.

Brooker, R. W., and R. V. Callaghan. 1998. The balance between positive and negative plant interactions and its relationship to environmental gradients: a model. Oikos 81:196-207.

Brooker, R. W., F. T. Maestre, R. M. Callaway, C. L. Lortie, L. A. Cavieres, G. Kunstler, P. Liancourt, K. Tielbörger, J. M. J. Travis, F. Anthelme, C. Armas, L. Coll, E. Corcket, S. Delzon, E. Forey, Z. Kikvidze, J. Olofsson, F. Pugnaire, C. L. Quiroz, P. Saccone, K. Schiffers, M. Seifan, B. Touzard, and R. Michalet. 2008. Facilitation in plant communities: the past, the present, and the future. Journal of Ecology 96:18-34.

Brose, P. H., D. C. Dey, and T. A. Waldrop. 2014. United States Forest Service, Northern Research Station. General Technical Report NRS-135.

Comita, L., H. Muller-Landau, S. Aguilar, and S. Hubbell. 2010. Asymmetric density dependence shapes species abundances in a tropical tree community. Science 329:330-332.

Condit, R., P. S. Ashton, P. Baker, S. Bunyavejchewin, S. Gunatilleke, N. Gunatilleke, S. P. Hubbell, R. B. Foster, L. Hua Seng, A. Itoh, J. V. LaFrankie, E. Losos, N. Manokaran, R. Sukumar, and T. Yamakura. 
2000. Spatial patterns in the distribution of common and rare tropical tree species: a test from large plots in six different forests. Science 288: 1414-1418.

Condit, R., S. P. Hubbell, and R. B. Foster. 1994. Density dependence in two understory tree species in a neotropical forest. Ecology 75:671-680.

Condit, R., P. Ashton, S. Bunyavejchewin, H. S. Dattaraja, S. Davies, S. Esufali, C. Ewango, R. Foster, I. A. U. N. Gunatilleke, C. V. S. Gunatilleke, P. Hall, K. E. Harms, T. Hart, C. Hernandez, S. Hubbell, A. Itoh, S. Kiratiprayoon, J. Lafrankie, S. L. de Lao, J.-R Makana, M. N. S. Noor, A. R. Kassim, S. Russo, R. Sukumar, C. Samper, H. S. Suresh, S. Tan, S. Thomas, R. Valencia, M. Vallejo, G. Villa, and T. Zillio. 2006. The importance of demographic niches to tree diversity. Science 313:98-101.

Condit, R. B. J. Le Boeuf, P. A. Morris, and M. Sylvan, M. 2007. Estimating population size in asynchronous aggregations: a Bayesian approach and test with elephant seal censuses, Marine Mammal Science 23:834-855.

Das, A., J. Battles, P. J. van Mantgem, and N. L. Stephenson. 2008. Spatial elements of mortality risk in old-growth forests. Ecology 89:1744-1756.

Davis, M. A. 2021. Twenty-five years of tree demography in a frequently burned oak woodland: implications for savanna restoration. Ecosphere (in press).

Davis, M. A., C. Curran, A. Tietmeyer, and A. Miller.2005. Dynamic tree aggregation patterns in a speciespoor temperate woodland disturbed by fire. Journal of Vegetation Science 16: 167-174.

Deitschmann, Glenn H. 1965. Bur oak (Quercus macrocarpa Michx.). In H. A. Fowells, comp. Silvics of forest trees of the United States. U.S. Department of Agriculture, Agriculture Handbook 271. Washington, DC. Pp. 563-568.

Dey, D. C., and C. Schweitzer. 2018. A Review on the Dynamics of Prescribed Fire, Tree Mortality, and Injury in Managing Oak Natural Communities to Minimize Economic Loss in North America. Forest 9:461. doi.org/10.3390/f9080461

Francis, R., and D. J. Read. 1984. Direct transfer of carbon between plants connected by vesicular-arbuscular mycorrhizal mycelium. Nature 307:53-56.

Frelich, L. E., S. Shinya, P. B. Reich, M. B. Davis, and S. K. Friedman. 1998. Neighbourhood effects in forests: implications for within stand patch structure. Journal of Ecology 86:149-161.

Frelich, L. E., P. B. Reich, and D. W. Peterson. 2015. Fire in Upper Midwestern Oak Forest Ecosystems: an Oak Forest Restoration and Management Handbook. Gen. Tech. Rep. PNW-GTR-914. Portland, OR: U.S. Department of Agriculture, Forest Service, Pacific Northwest Research Station. 64 p.

Frost P.G.H., and F. Robertson. 1987. The ecological effects of fire on savannas. In B. H. Walker, editor. Determinants of Tropical Savannas. ICSU Press, Miami. Pp. 93-140.

Germain, S. J., and J. A. Lutz. 2021. Shared friends counterbalance shared enemies in old forests. Ecology 102: https://doi.org/10.1002/ecy.3495

Gibbs, J. N., and D. W. French. 1980. The transmission of oak wilt. U.S. Department of Agriculture Forest Service, Research Paper NC-185, 17 p. U.S. Department of Agriculture Forest Service, North Central Forest Experiment Station, St. Paul, Minnesota.

Grigal, D. F., L. M. Chamberlain, H. R. Finney, D. V. Wroblewki, and E. R. Gross. 1974. Soils of the Cedar Creek Natural History Area. Miscellaneous Report 123. University of Minnesota Agricultural Experimental Station, Saint Paul, Minnesota, USA.

Guo, Y, H. Y. H. Chen, B. Wang, W. Xiang, D. Li, X Li, A. U. Mallik, T. Ding, F. Huang, S. Lu, and S. Wen. 2021. Conspecific and heterospecific crowding facilitate tree survival in a tropical karst seasonal rainforest. Forest Ecology and Management, https://doi.org/10.1016/j.foreco.2020.118751 
Hoffmann, W. A., S. Y. Jaconis, K. L. Mckinley, E. L. Geiger, S. G. Gotsch, and A. Franco. 2012b. Fuels or microclimate? Understanding the drivers of fire feedbacks at savanna-forest boundaries. Austral Ecology 37:634-643.

Holdo, R. M. 2005. Stem mortality following fire in Kalahari sand vegetation: effects of frost, prior damage, and tree neighbourhoods. Plant Ecology 180:77-86.

Howe, H. F., and J. Smallwood. 1982. Ecology of seed dispersal. Annual Review of Ecology and Systematics $13: 201-228$

Irving, F. D. 1970. Field instruction in prescribed burning techniques at the University of Minnesota. Proceedings of the Tall Timbers Fire Ecology Conference 10:323-331.

Jagemann, S.M., J. Juzwik, P. C. Tobin, and K. F. Raffa. 2018. Seasonal and regional distributions, degreeday models, and phoresy rates of the major sap beetle (Coleoptera: Nitidulidae) vectors of the oak wilt fungus, Bretziella fagacearum, in Wisconsin. Environmental Entomology 47:1152-1164.

Johnson, Paul S. 1990. Quercus macrocarpa Michx. bur oak. In: R. M. Burns, B. H. Honkala, technical coordinators. Silvics of North America. Volume 2. Hardwoods. Agricultural Handbook 654. Washington, DC: U.S. Department of Agriculture, Forest Service. Pp. 686-692.

Juzwik, J., D. N. Appel, W. L. Macdonald, and S. Burks. 2011. Challenges and successes in managing oak wilt in the United States. Plant Disease 95:888-900.

Kenfack, D., G. Chuyong, R. Condit, R. Russo, and D. Thomas. 2014. Demographic variation and habitat specialization of tree species in a diverse tropical forest of Cameroon. Forest Ecosystems 1:1-13.

Kuntz, J.E., and A. J. Riker. 1956. The use of radioactive isotopes to ascertain the role of root grafting in the translocation of water, nutrients, and disease-inducing organisms among forest. In J. G. Beckerly, editor. Proceedings, International Conference on Peaceful Uses of Atomic Energy, volume 12. Geneva, Switzerland. Pp. 144-148.

Larson, A. J., and D. Churchill. 2012. Tree spatial patters in fire-frequent forests of western North America, including mechanisms of pattern formation and implications for designing fuel reduction and restoration treatments. Forest Ecology and Management 267:74-92.

Larson, A. J., J. A. Lutz, D. C. Donato, J. A. Freund, M. E. Swanson, J. HilleRisLambers, D. G. Sprugel, J. F.Franklin. 2015. Spatial aspects of tree mortality strongly differ between young and old-growth forests. Ecology 96: 2855-2861.

Lorimer, C.G. 1985. The role of fire in the perpetuation of oak forests. In: J. E. Johnson, editor. Proceedings: Challenges in oak management and utilization. Madison, Wisconsin: Extension Service, University of Wisconsin. Pp. 8-25.

Lutz, J. A., A. J. Larson, T. J. Furniss, D. C. Donato, J. A. Freund, M. E. Swanson, K. J. Bible, J. Chen, and J. F. Franklin. 2014. Spatially nonrandom tree mortality and ingrowth maintain equilibrium pattern in an old-growth Pseudotsuga-Tsuga forest. Ecology 95:2047-2054.

Meddens, A. J. H, C. A. Kolden, J. A. Lutz, J. T. Abatzoglou, and A. T. Hudak. 2018. Spatiotemporal patterns of unburned areas within fire perimeters in the northwestern United States from 1984 to 2014. Ecosphere 9, e02029. doi.org/10.1002/ecs2.2029

Meyer K. M., D. Ward, K. Wiegand, and A. Moustakas. 2008. Multi-proxy evidence for competition between savanna woody species. Perspectives in Plant Ecology, Evolution and Systematics 10:63-72.

Pellegrini, F. A., A. M. Hein, J. Cavender-Bares, R. A. Montgomery, A. C. Staver, F. Silla, S. E. Hobbie, and P. B. Reich. 2021. Disease and fire interact to influence transitions between savanna-forest ecosystems over a multi-decadal experiment. Ecology Letters 24:1007-1017. 
Peterson, D. W., and P. B. Reich. 2001. Prescribed fire in oak savanna: fire frequency effects on stand structure and dynamics. Ecological Applications 11:914-927.

Peterson, D. W., P. B. Reich, and K. J. Wrage. 2007. Plant functional group responses to fire frequency and tree canopy cover gradients in oak savannas and woodlands. Journal of Vegetation Science 18:3-12.

Peterson C. J. 2020. Change in tree spatial pattern after severe wind disturbance in four North American northern hardwood and sub-boreal forests. Frontiers in Forests and Global Change 3:57. doi: $10.3389 /$ ffgc. 2020.00057

Pineda, A., S-J Zheng, J. J. A. van Loon, C. M. J. Pieterse, and M. Dicke. 2010. Helping plants to deal with insects: the role of beneficial soil-borne microbes. Trends in Plant Science 15:507-514.

Rebertus, A.J., and B.R. Burns. 1997. The importance of gap processes in the development and maintenance of oak savannas and dry forests. Journal of Ecology 85: 635-645

Rebertus, A. J., G. B. Williamson, and E. B. Moser. 1989. Fire induced changes in Quercus laevis spatial pattern in Florida sandhills. Journal of Ecology 77:638-650.

Sapes, G. C. Lapadat, A. K. Schweiger, J. Juzwik, R. Montgomery, H. Gholizadeh, P. A. Townsend, J. A. Gamon, and J. Cavender-Bares. 2021. Canopy spectral reflectance detects oak wilt at the landscape scale using phylogenetic discrimination. bioRxiv preprint doi: https://doi.org/10.1101/2021.01.17.427016

Scholes, R. 2003. Convex Relationships in Ecosystems Containing Mixtures of Trees and Grass. Environmental and Resource Economics 26:559-574.

Simard, S., D. Perry, M. D. Jones, D. D. Myrold, D. M. Durall, and R. Molina. 1997. Net transfer of carbon between ectomycorrhizal tree species in the field. Nature 388:579-582.

Snyder, R. E. 2011. Leaving home ain't easy: non-local seed dispersal is only evolutionarily stable in highly unpredictable environments. Proceedings of the Royal Society B 278: 739-744.

Staver, A. C., G. P. Asner, I Rodriquez-Iturbe, S. A. Levin, and I. P. J. Smit. 2019. Spatial patterning among savanna trees in high-resolution, spatially extensive data. Proceedings of the National Academy of Science 116:10681-10685.

Stephens, S. L., D. L. Fry, and E. Franco-Vizcaino. 2008. Wildfire and spatial patterns in forests in northwestern Mexico: the United States wishes it had similar fire problems. Ecology and Society 13 Ecology and Society 13, doi.org/10.5751/ES-02380-130210

Stratton, R.L. 2007. Effects of long-term late winter prescribed fire on forest stand dynamics, small mammal populations, and habitat demographics in a Tennessee oak barrens. M.S. thesis. University of Tennessee, Knoxville, Tennessee.

Tamjidi, J., and J. A. Lutz. 2020. The Post-Fire Assembly Processes of Tree Communities Based on Spatial Analysis of a Sierra Nevada Mixed-Conifer Forest. Fire 3:72. https://doi.org/10.3390/fire3040072

Teste, F. P., and S. W. Simard. 2008. Mycorrhizal networks and distance from mature trees alter patterns of competition and facilitation in dry Douglas-fir forests. Oecologia 158:193-203.

Tirado, R., and F. I. Pugnaire. 2005. Community structure and positive interactions in constraining environments. Oikos 111: 437-444.

Turner, M. G. 1989. Landscape ecology: the effect of pattern on process. Annual Review of Ecology and Systematics 20:171-197.

Van der Heijden, M. G. A., and T. R. Horton. 2009. Socialism in soil? The importance of mycorrhizal fungal networks for facilitation in natural ecosystems. Journal of Ecology 97:1139-1150. 
Walker, J. F. 2003. Diversity and ecology of mycorrhizal fungi associated with oak seedlings in the Appalachian Mountains. PhD dissertation, Virginia Polytechnic Institute and State University, Blacksburg, Virginia, USA.

Walker, L. R., and F. S. Chapin, F. S. 1987. Interactions among Processes Controlling Successional Change. Oikos:131-135.

Wenny, D. G. 2001. Advantages of seed dispersal: A re-evaluation of directed dispersal. Evolutionary Ecology Research 3:51-74.

Wovcha, D. S., B. C. Delaney, G. E. Nordquist, T. R. Klein, and A. Epp. 1995. Minnesota's St. Croix River Valley and Anoka Sandplain: A Guide to Native Habitats. University of Minnesota Press, Minneapolis, Minnesota, USA.

\section{FIGURE LEGENDS}

Histogram of A) untransformed growth (dbh increment) and B) growth transformed by

the power 0.45 . Vertical red lines are at the mean and 3 standard deviations above the mean. In panel B, the leftmost bar, near 0 , includes the 6 trees with exactly 0 growth; in panel A, the leftmost bar includes the zeroes plus those at $\mathrm{g}=0.2$. Data are from $Q$. ellipsoidalis, using growth from census 6 to 11, including stems [?] 10 but $<20 \mathrm{~cm}$ dbh.

1. Effect sizes of four neighborhood parameters on survival in Q. macrocarpa : conspecific basal area within $10 \mathrm{~m}$ (consp. <10) and at 10-20 m (consp. 10-20); heterospecific basal area within $10 \mathrm{~m}$ (heterosp. <10) and at 10-20 m (hetersp. 10-20). Positive effect sizes mean increased survival; negative effect sizes mean reduced survival. A single model was run for each of the three dbh classes; each included census interval as a random effect. The three dbh classes are separated by color; the six census intervals by shape. Vertical dashed lines are $95 \%$ credible intervals, which are 95th percentiles of posterior distributions of each parameter, the post-burn-in parameter chains.

2. Effect sizes of five parameters describing local neighborhoods on survival in Q. ellipsoidalis . See Fig. 2.

3. Effect sizes of four neighborhood parameters on growth in Q. macrocarpa : conspecific basal area within $10 \mathrm{~m}$ (consp. <10) and at 10-20 m (consp. 10-20); heterospecific basal area within $10 \mathrm{~m}$ (heterosp. $<10$ ) and at 10-20 m (heterosp. 10-20). Positive effect sizes mean increased growth rates. Negative effect sizes mean reduced growth rates. A single model was run for each of the three dbh classes; each included census interval as a random effect. The three dbh classes are separated by color; the six census intervals by shape. Vertical dashed lines are $95 \%$ credible intervals, which are 95 th percentiles of posterior distributions of each parameter, the post-burn-in parameter chains.

4. Effect sizes of five parameters describing local neighborhoods on growth in Q. ellipsoidalis . See Fig. 4.

Figure 1 

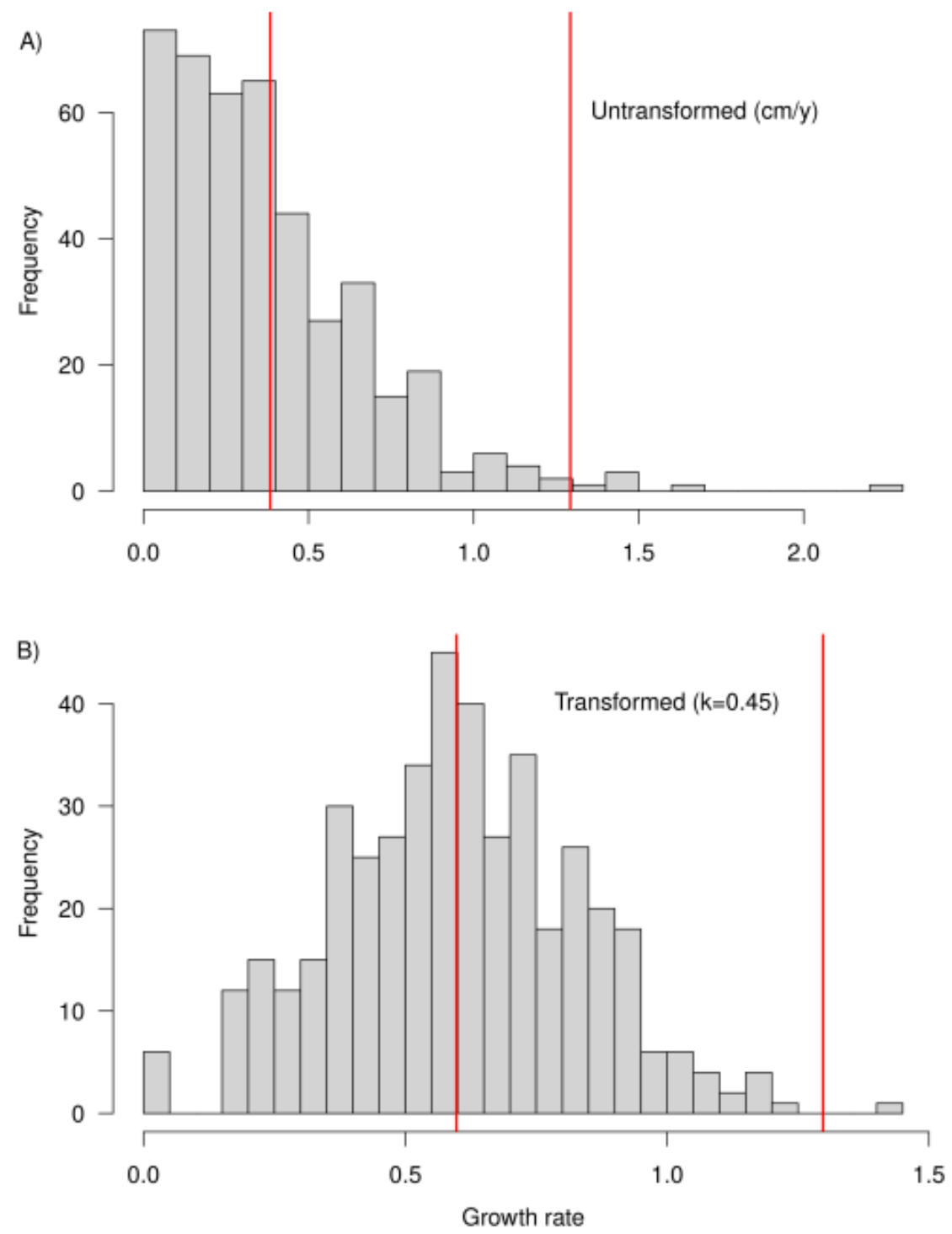

Figure 2 


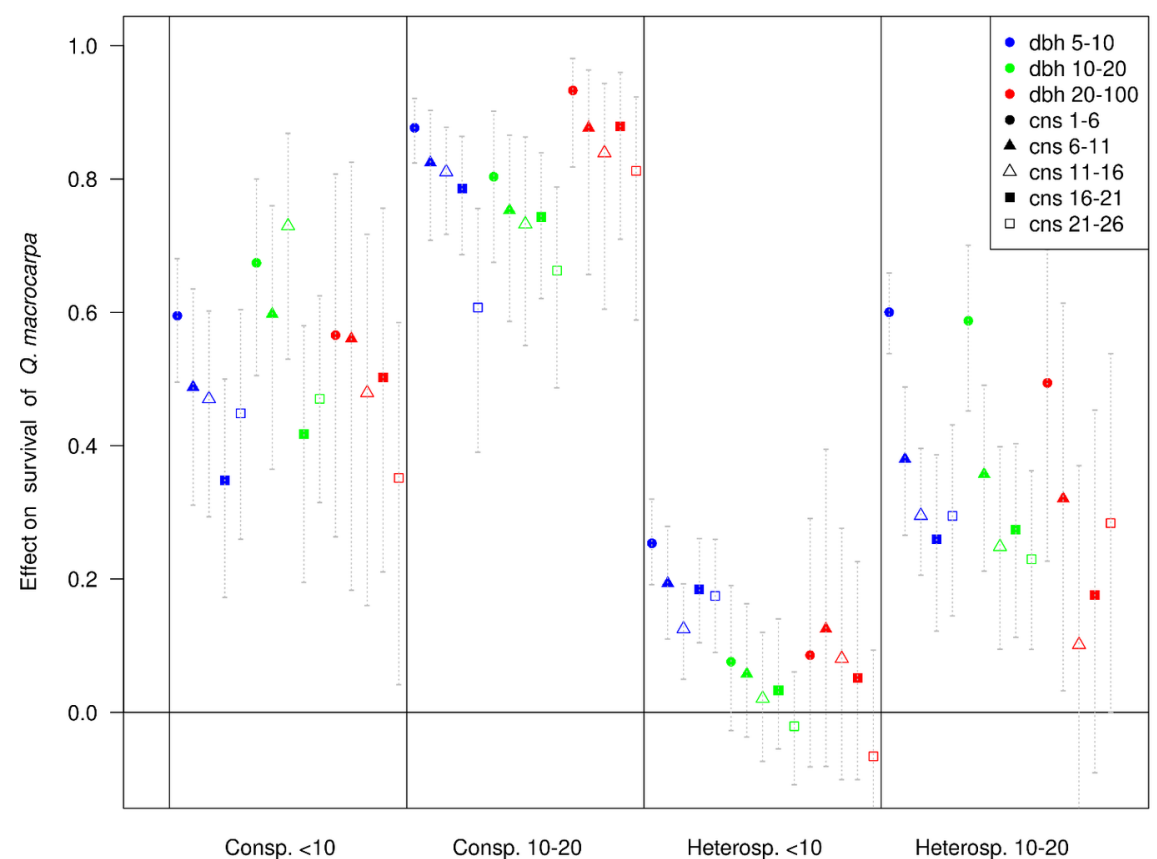

Figure 3

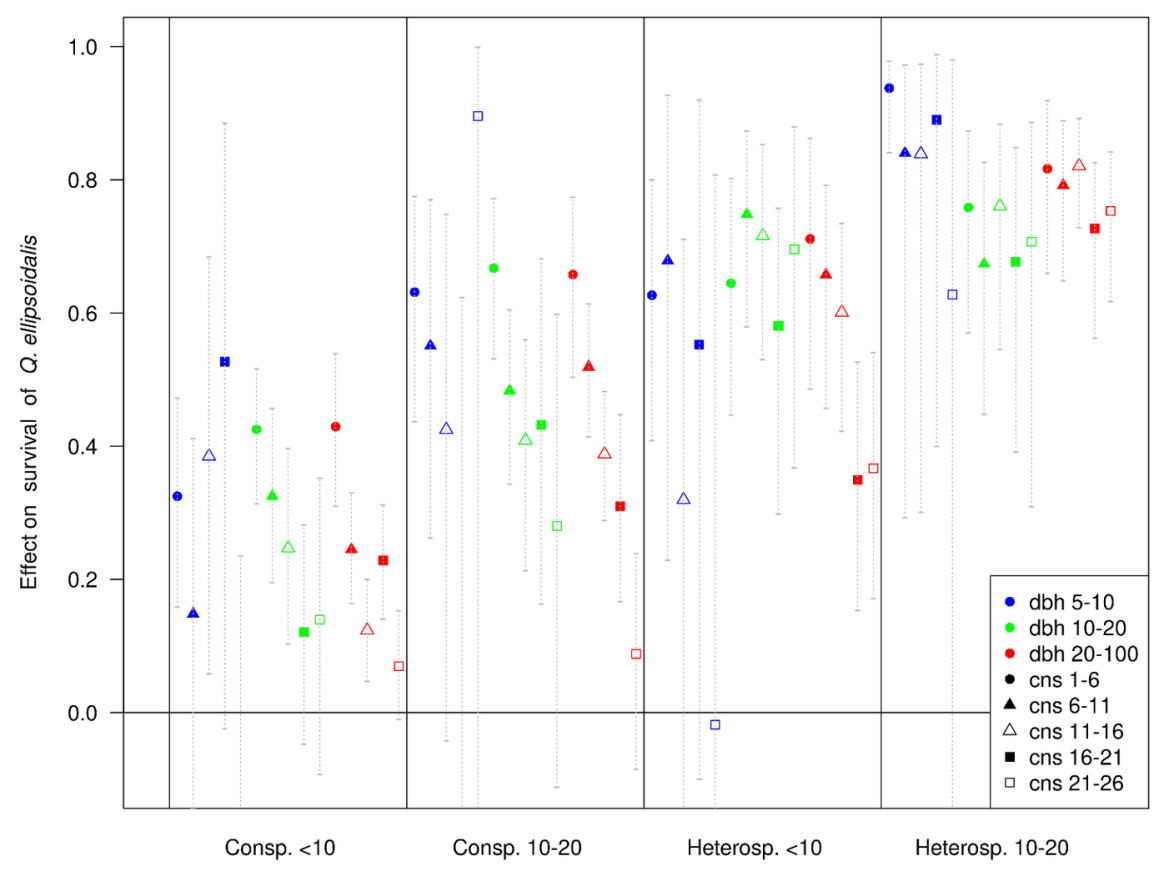

Figure 4 


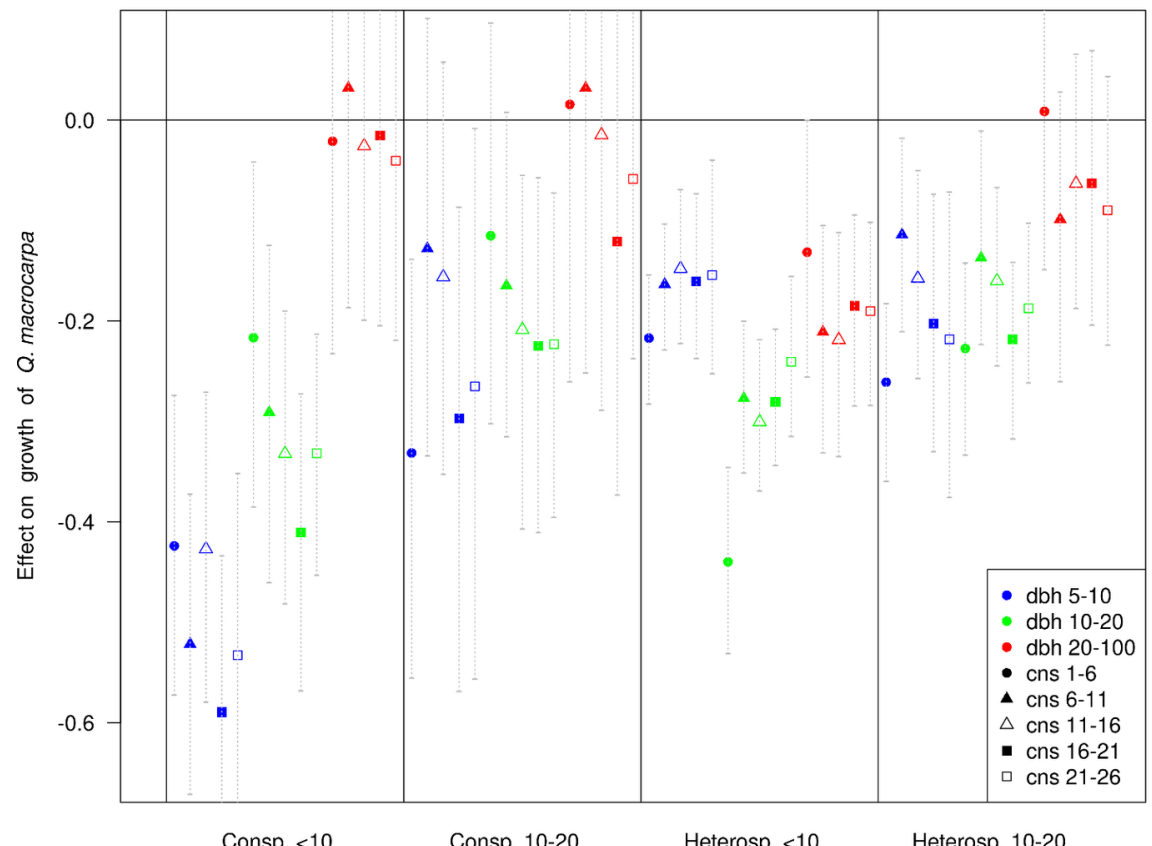

Figure 5

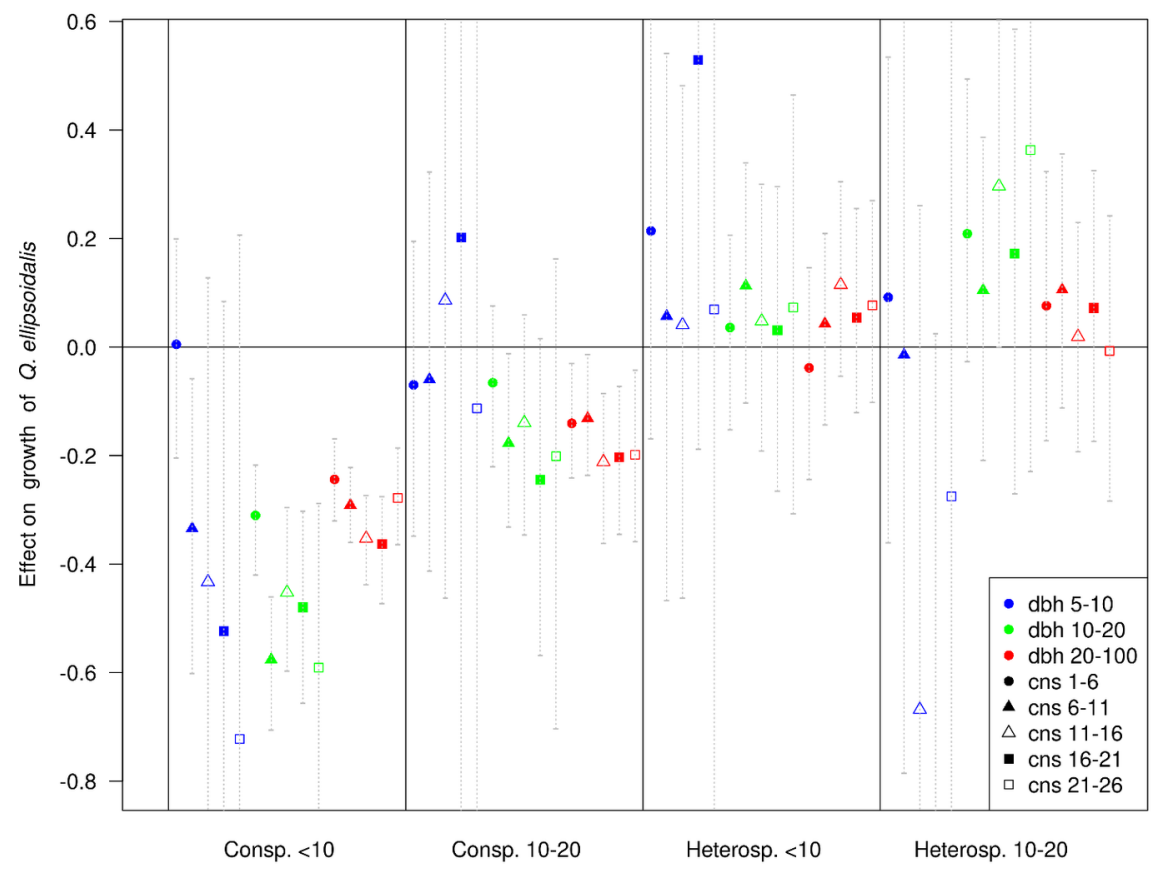

